\title{
LEDGF/p75 and transportin-SR2 are cellular cofactors of HIV integrase and novel targets for antiviral therapy
}

The HIV replication cycle is an elaborate interplay between the viral machinery and cellular proteins. In this review we propose that protein-protein interactions between cellular proteins and HIV integrase are new targets for future antiviral therapy. We focus on the early steps of HIV replication, namely viral entry, uncoating, reverse transcription, trafficking, nuclear import and integration, and the host cell proteins involved herein. We then discuss the feasibility of developing small-molecule protein-protein interaction inhibitors as antiviral agents. Next, we review the HIV integrase cofactors described in the literature highlighting two validated cofactors, lens epitheliumderived growth factor/p75 and transportin-SR2, which are discussed in detail. Finally, a speculative viewpoint is given on small-molecule protein-protein interaction inhibitors as future HIV inhibitors.

KEYWORDS: AIDS antiviral therapy cofactor HIV integration LEDGF/p75 nuclear import protein-protein interaction transportin-SR2

\section{HIV therapy \& drug discovery}

The standard therapy for HIV-1-infected patients, HAART, is based on cocktails of potent drugs targeting different steps of the replication cycle. The drugs fall into three main classes: protease inhibitors, nucleoside or nucleotide reverse transcriptase inhibitors and non-nucleoside reverse transcriptase inhibitors. Combinations of these drugs are given to maximize viral suppression and minimize the risk of resistance development. Lately, novel drugs targeting other steps of the viral life cycle have entered the clinic to complement standard HAART: enfuvirtide (fusion inhibitor), maraviroc (CCR5 coreceptor inhibitor) and raltegravir (integrase [IN] inhibitor).

Owing to its short replication cycle and higherror rate, HIV mutates very quickly resulting in the rapid emergence of drug-resistant HIV strains, urging scientists to constantly look for second generation inhibitors and novel drug targets to outpace resistance development. To avoid cross-resistance, novel drugs preferentially target as yet unexploited steps of the viral replication cycle. Although antiviral drugs typically target viral proteins to reach specificity, we propose to use our expanding knowledge on cellular cofactors to target protein-protein interactions (PPIs) between HIV and cellular proteins.
The HIV replication cycle is an elaborate interplay between the viral machinery and proteins of the invaded cell. Cellular proteins recruited by the virus to aid its propagation are referred to as cofactors whereas proteins that counteract certain steps of the HIV life cycle and mount an innate antiviral defense are termed restriction factors. Only in permissive cells, such as macrophages and metabolically active $T$ cells, does the resulting equilibrium lead to a productive infection. Future HIV research will thus be intimately coupled to cell biology. We will focus here on the early steps of HIV replication and review the cellular cofactors of HIV integration. We will highlight two recently validated cofactors, lens epitheliumderived growth factor (LEDGF/p75) and transportin-SR2 (TRN-SR2), in light of the development of novel antiviral drugs. Since both drug targets involve PPIs we include a digression on the development of drugs targeting PPIs.

\section{Early steps of the HIV replication cycle}

- Entry, uncoating, trafficking

\& reverse transcription

The HIV replication cycle is initiated by the attachment of the viral envelope glycoprotein gp120 to the cellular CD4 receptor (Figure I). The interaction of gp120 and CD4 triggers a
Wannes Thys, Katrien Busschots, Melissa McNeely, Arnout Voet, Frauke Christ \& Zeger Debyser ${ }^{\dagger}$ †Author for correspondence: Molecular Medicine, KU Leuven Kapucijnenvoer 333000 Leuven, Flanders, Belgium Tel.: +32 I633 2183; Fax: +32 1633 6336; E-mail: zeger.debyser@med. kuleuven.be 


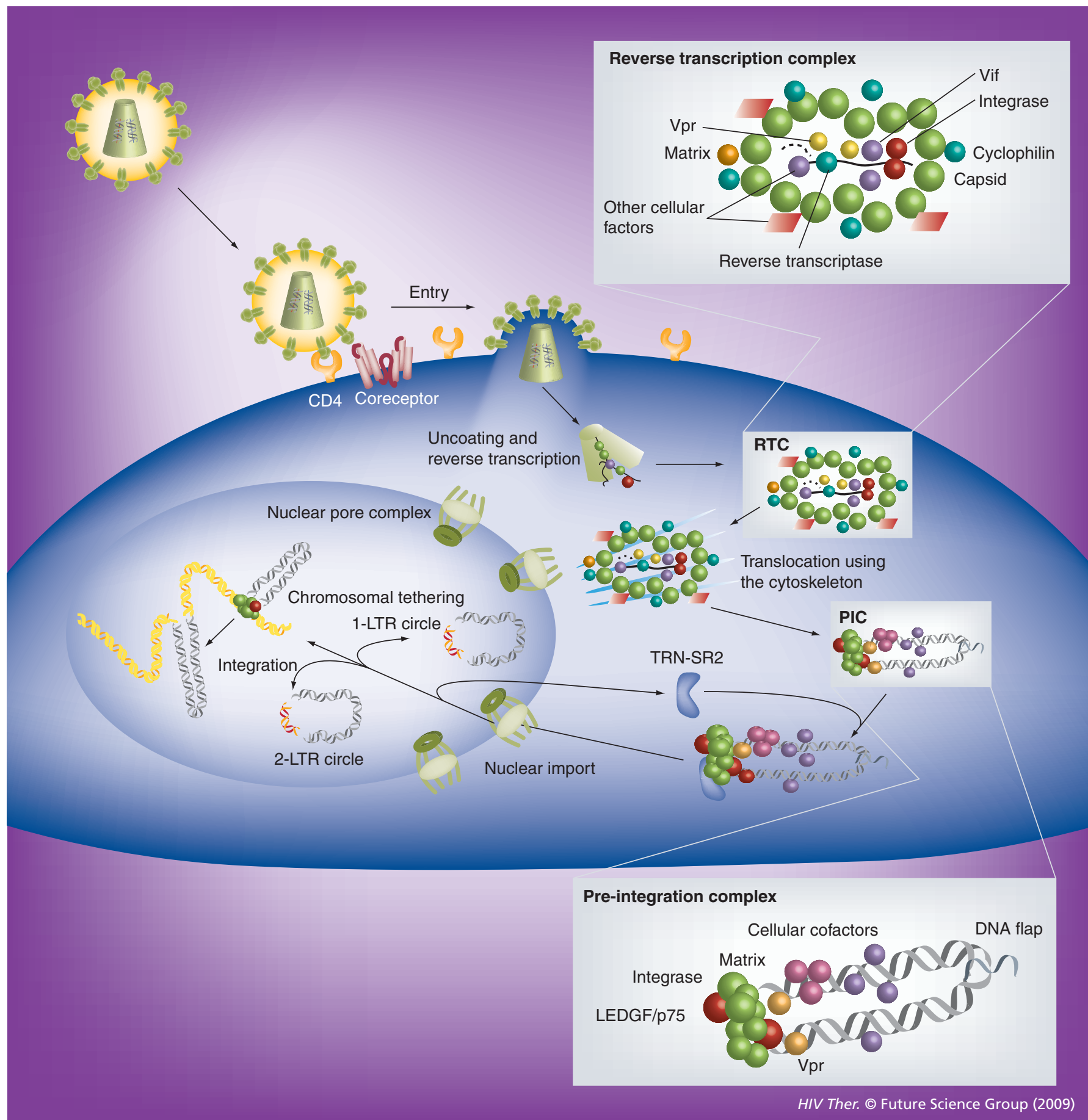

Figure 1. Early steps of HIV-1 replication. Entry of the viral particle into the target cell starts with the interaction of the viral envelope protein with the CD4 surface receptor. This binding triggers a conformational change in the gp120 molecule, enabling binding to the CXCR4 or CCR5 chemokine coreceptor. Binding to the coreceptor induces a conformational change in the viral gp41 protein of the viral envelope, and induces fusion of the viral particle with the cellular membrane. Upon injection of the viral core into the cytoplasm, uncoating and reverse transcription are initiated in a nucleoprotein complex called the RTC. During reverse transcription, the viral RNA is copied into double-stranded cDNA. Using the cytoskeleton (blue), the RTC is transported towards the nucleus. After completion of reverse transcription, the viral complex is referred to as the viral PIC. Transport through the nuclear membrane most probably takes place through the nuclear pore complex and is mediated by TRN-SR2 as was recently discovered. In the nucleus, the PIC is tethered to the chromosomes by LEDGF/p75 prior to integration into the host genome. Common dead-end by-products of viral replication are 1-LTR and 2-LTR circles formed in the nucleus of the cell.

LEDGF: Lens epithelium-derived growth factor; LTR: Long terminal repeats; PIC: Pre-integration complex; RTC: Reverse transcription complex; TRN: Transportin. 
conformational change in the gp120 molecule, which allows binding to the CXCR 4 or CCR5 chemokine coreceptor. This interaction causes a conformational change in the gp41 viral transmembrane protein that provokes penetration of the gp 41 protein into the cellular membrane and fusion of the viral and cellular membranes. Upon fusion, the contents of the HIV virion, the virus core, are released into the cytoplasm. Subsequent disassembly or uncoating of the viral core by a poorly understood mechanism results in the formation of a reverse transcription complex (RTC), comprised of HIV RNA, the viral proteins reverse transcriptase, matrix protein (MA), viral protein $\mathrm{R}(\mathrm{Vpr})$ and IN, as well as a largely unexplored number of cellular proteins. Reverse transcription of the positive RNA strand is initiated by reverse transcriptase that copies the single-stranded viral RNA into double-stranded cDNA. The initiation of reverse transcription seems to be coupled to the onset of viral core uncoating [1], although the capsid may remain intact for at least a portion of the reverse transcription process as was observed by fluorescence microscopy [2]. The HIV capsid (CA) protein has been shown to interact with the cellular protein cyclophilin A (CypA; for a review see [3]). CypA is a ubiquitous cytoplasmic protein that catalyzes the cis/trans isomerization of peptidyl-prolyl bonds. The peptidyl-prolyl bond linking CA residues G89 and P90 undergoes isomerization. Although the significance of this catalytic activity of CypA is unknown, the CypA-CA interaction does promote an early step in HIV replication [4]. To reach the nuclear envelope, the RTC must travel from the plasma membrane through the cytoplasm to the nucleus. The high viscosity of the cytoplasm means that movement of these particles by diffusion is likely to be very limited, especially considering the size of the RTC, which has been estimated to be at least $50 \mathrm{~nm}$ in diameter [5]. To be able to move through the highly viscous medium, HIV utilizes the cellular cytoskeleton. Live-cell microscopy has shown that HIV virion trafficking first occurs in the cortical regions of the host cell cytoplasm. These movements are likely due to an interaction of viral particles with the actin microfilaments of the host cell. However, subsequent translocation of the RTC towards the nucleus takes place along the microtubule network [2]. Little is known about the viral proteins mediating the interactions with the cytoskeleton. The viral MA and CA proteins were shown to associate with the actin cytoskeleton [6] and microtubules [2], respectively, suggesting that they are involved in actin-mediated movement and the transition of viral cores to the microtubule network [7]. Reverse transcription occurs during HIV RTC transport through the cytoplasm and is almost completed by the time the complex reaches the nucleus. The newly formed viral cDNA remains associated with viral and cellular proteins in a nucleoprotein complex that is now capable of integration, and therefore is termed the pre-integration complex (PIC) (Figure I). It should be noted here that the distinction between RTCs and PICs is somewhat arbitrary, since uncoating is believed to occur progressively during reverse transcription. PICs are usually defined as the integration-competent complexes, whereas reverse transcription is still incomplete in RTCs. Also, attempts to determine the exact composition of RTCs and/or PICs have not yielded clear answers, since the nature of the viral and cellular components found in these nucleoprotein complexes depends on the techniques used to purify the complexes, which are highly sensitive to detergents [8].

\section{- Nuclear import}

Since reverse transcription takes place in the cytoplasm the PIC must be transported across the nuclear envelope before IN can mediate integration of the proviral DNA into the host chromosome. For most retroviruses, the PIC is unable to access the nucleus unless the host cell is in mitosis, presumably because nuclear envelope breakdown allows unrestricted passage of the PIC to the nucleus. Since HIV can infect nondividing cells such as macrophages, dendritic cells and helper $T$ cells, transport through the nuclear pore complex (NPC) is required to reach the host cell chromosomes. The NPC regulates cargo transport between the cytoplasm and the nucleus. Each vertebrate NPC is an approximately $120 \mathrm{MDa}$ macromolecular assembly comprising approximately 30 different proteins, known as nucleoporins, that surround a central pore measuring approximately $40 \mathrm{~nm}$ in diameter in the midplane of the nuclear envelope [9]. The passive diffusion size limit of the NPC is approximately $9 \mathrm{~nm}$ in diameter, so small molecules such as ions, metabolites and intermediate-sized macromolecules can pass the NPC unassisted by diffusion [10]. For the PIC, which has an estimated diameter of at least $50 \mathrm{~nm}$ [5], passive diffusion as a viable mechanism for translocation is impossible and active cellular transport mechanisms are required.

Macromolecules that are greater than approximately $40 \mathrm{kDa}$ are transported actively across the nuclear envelope using soluble transport 
factors or carrier molecules that cycle between the cytoplasm and the nucleus. There are several nuclear transport pathways, each of which transports a specific range of macromolecules into or out of the nucleus. Most pathways use the large, evolutionarily conserved, karyopherin family of proteins, which consists of import carriers called importins and export carriers called exportins. Karyopherins have comparable molecular weights $(95-145 \mathrm{kDa})$ and a similar domain structure, which consists of an aminoterminal Ran-binding domain, a central nucleoporinbinding domain and a carboxyterminal cargobinding domain. There are different protein import pathways using different carriers, but they all share common features and are based on a concerted series of PPIs. These can be divided into four steps:

- Assembly of the cargo-carrier import complex

- Translocation through NPCs

- Cargo-carrier complex disassembly in the nucleus

- Importin recycling (for a review see [11])

Importins bind to their cargoes in the cytoplasm either directly or indirectly by an adaptor protein via recognition of a nuclear localization signal (NLS) sequence motif. There are different classes of NLS, each of which is recognized by the transport factors of a different pathway. There are many more cargoes than karyopherins, suggesting that each karyopherin transports multiple cargoes and can recognize different NLS. The classic NLS contains one (monopartite) or two (bipartite) clusters of basic residues, and are recognized by importin- $\alpha$, an adaptor protein that binds to importin- $\beta$, which imports the complex into the nucleus. Importin- $\beta$, however, can also bind directly to its cargo, for example, the HIV proteins Tat and Rev, without interacting with an adaptor protein.

The molecular mechanism by which retroviral PICs cross the nuclear envelope in nondividing cells is still poorly understood. Generally it is believed that the PIC translocates through the NPC by means of an importin recognizing one or more karyophilic signals in the PIC. Multiple NLS were found in the PIC, all of which have been proposed to mediate nuclear import of the PIC. MA, Vpr as well as IN are thought to contain at least one NLS, but many conflicting papers indicate that none of them are the sole determinant of the ability of HIV-1 PICs to pass through the nuclear membrane (for a review see [12]). The DNA flap, a triple-stranded DNA overhang formed during reverse transcription, has also been shown to be important for nuclear import and viral replication [13-16]. At present it is not known which karyophilic element in the PIC mediates transport across the nuclear envelope into the nuclear periphery. Until recently, it was also unclear which importin transports the PIC through the NPC (for a review see [17]). Importin- $\alpha,-\beta$ and-7 have all been implicated in the nuclear import of the HIV PIC. However, recent reports have described TRN-SR2 as being the nuclear import factor of the HIV-1 PIC [18-20].

Bidirectional protein transport between the cytoplasm and nucleus is an important signaling mechanism responsible for the regulation of gene expression, DNA synthesis and cell cycling, and can constitute a new therapeutic target. Agents affecting nuclear translocation can be used to improve gene and drug delivery, to modulate steroid receptor transport for anti-inflammatory therapy, and in anticancer and antiviral strategies [21]. Unraveling of the precise import mechanism used by the HIV PIC could also disclose new therapeutic targets for anti-HIV therapy. The main hurdle to the study of nucleocytoplasmic trafficking of HIV was the lack of an in vivo assay that allows direct detection of nuclear import of viral genomes in living cells. In vitro import assays with digitonin-permeabilized cells and individual HIV proteins may not accurately reflect natural infection. Recently, methods were developed to detect labeled HIV PICs by fluorescence microscopy; and they provide a powerful tool for tracking single viral particles and studying the role of cellular import factors in HIV replication [22,23].

\section{- Integration}

In the nucleus the proviral DNA associates with the host chromosomes and viral cDNA integration takes place. This step is catalyzed by IN and is referred to as 'the point of no return' since from that moment on the provirus will form part of the cellular genome. It is important to understand that HIV integration is a multistep process that takes place in different compartments in the cell. It can be divided into the following steps:

$$
\begin{aligned}
& \text { - Formation of the IN-viral DNA complex } \\
& \text { - 3'-processing of viral DNA ends } \\
& \text { - Nuclear import of the PIC } \\
& \text { - Target-site selection }
\end{aligned}
$$


- Strand transfer into the host chromosome

- Repair of the ssDNA gaps remaining at the viral-chromosomal DNA junctions after integration

During the 3 '-processing reaction in the cytoplasm, IN hydrolyzes a pGT dinucleotide from each 3 '-end of the viral long terminal repeats, adjacent to a highly conserved CA dinucleotide. The subsequent strand transfer reaction occurs in the nucleus following nuclear import of the PIC. The viral IN mediates a concerted nucleophilic attack by the 3'-hydroxyl residues of the viral DNA on phosphodiester bridges located on either side of the major groove in the target DNA. Next, the processed CA-3'-OH viral DNA ends are ligated to the 5'-O-phosphate ends of the target DNA. Since the 3'-ends of the target DNA remain unjoined after the strand transfer, the product is a gapped intermediate product in which the 5'-phosphate ends of the viral DNA are not attached to the $3^{\prime}-\mathrm{OH}$ ends of the host DNA [24]. The integration process is completed by cleavage of the unpaired dinucleotides from the 5'-ends of the viral DNA and repair of the single-stranded gaps created between the viral and target DNA. This repair is probably mediated by cellular DNA repair enzymes [25]. Although purified HIV-1 IN is sufficient to catalyze the DNA breakage and joining steps of the integration process in a test tube in the absence of any other protein factor, a number of studies indicate that cellular proteins participate as cofactors in the integration of the reverse transcribed viral cDNA in the host cell genome. Before describing two HIV IN cofactors in detail, we will first address the feasibility of targeting PPIs with small molecules in antiviral therapy.

\section{Protein-protein interactions \& drug development}

Many proteins exert their biological roles as components of complexes, and the functions of proteins are often determined by their specific interactions with other proteins. These PPIs play a key role in most biological processes - as varied as cytoskeletal remodeling, vesicle transport, signal transduction or programmed cell death and therefore the ability to interfere with specific PPIs provides a powerful tool to influence the function of selected proteins within the cell in order to study physiological cellular processes and for treatment of numerous diseases. PPIs thus represent a large and important class of therapeutic targets [26-28]. The wealth of information obtained from the fields of genomics and proteomics has increased the number of known PPIs involved in the pathogenesis of various human diseases. Nevertheless, these interactions have traditionally been considered to be more difficult targets than enzymes or receptors. The most attractive class of inhibitors consists of small-molecule PPI inhibitors (SMPPIIs). These benefit from several attractive properties, such as the relatively simple and inexpensive production process in comparison to that of antibody or peptide synthesis. Moreover, as the cell membrane is permeable to many small-molecule inhibitors, they are useful as oral therapeutics. So far, several protein-protein interfaces have been identified as putative targets and a few SMPPIIs are currently in clinical trials as discussed below. Despite the fact that none of these compounds have reached the pharmaceutical market yet, small-molecule antagonists of PPIs hold a promise for future therapies of human disease, including cancer and viral infections. Methods for unraveling protein interaction hotspots, for identification of structural motifs common to protein interaction interfaces and for mapping protein-protein contact surfaces have all contributed to the design of SMPPIIs.

The identification or design of SMPPIIs is considerably more difficult than the development of inhibitors targeting active sites of enzymes or ligand-binding pockets. First, active sites or binding pockets of receptors are intrinsically shaped to strongly bind small molecules. Furthermore, the knowledge of natural ligands and substrates of receptors and enzymes provides an initial template for the de novo rational design of inhibitors. This stands in stark contrast to PPI sites, which by definition do not bind small ligands that could serve as a template for the design of SMPPIIs. A second problem is that the area of the recognition sites in protein-protein complexes is often greater than $1100 \AA^{2}$, with the exact area depending on the nature of the complex [29]. This vastly exceeds the potential binding area of a low-molecular-weight compound. However, it has become clear that the free energy of binding is not evenly distributed across protein-protein interfaces; instead, there are 'hotspots' of free energy of binding made up of a small subset of residues near the center of the dimer interface $[30,31]$. Such hotspots appear to be common in PPIs [31]. A well engineered small molecule could bind to such a hotspot and form a small-molecule protein complex with 
altered topographical and electrostatic properties preventing the binding of the protein's cognate ligand. A third challenge in the search of potent SMPPIIs is the flatness of most protein interfaces. X-ray structures have shown that a large part of the surface area of a typical protein-protein interface is buried, with the atoms closely packed together, implying that only a few cavities or binding pockets are available for small-molecule binding. Fourth, analysis of protein contacts has revealed that interface surfaces are quite complementary to each other, both in shape and in the juxtaposition of hydrophobic, polar and charged amino acids. This apparent complementarity between two surfaces involves a significant degree of protein flexibility and adaptivity because many proteins function by binding to multiple partners and the binding partners sometimes tend to use the same hotspot. Therefore, protein-binding hotspots can adapt to present the same residues for binding to a variety of proteins in different structural contexts [32]. The plasticity of protein-protein interfaces makes protein-structure-based predictions of chemical entities suitable for the modulation of the respective interaction a more challenging task, because the structural and functional adaptivity of protein interfaces can produce binding-site conformations that are well suited to small-molecule binding yet may not be visible in a single crystal structure [33,34]. A fifth difficulty in the design of SMPPIIs is the size and character of typical small-molecule libraries. Available libraries of compounds are typically derived from historical medicinal chemistry efforts in pharmaceutical companies. Therefore, they are usually designed to span the characteristics of classical drug targets and are not specifically adapted to the characteristics of PPIs. Nevertheless, several lead compounds were identified by high-throughput screening (HTS) involving small-molecule libraries [35-39]. A recently developed, more advanced method of HTS is called fragment-based drug discovery [40], in which very small molecules (fragments) are screened and the generally low potency hits are then linked to other low affinity binders to form the final high affinity molecule. This approach has generated a significant number of novel small molecules with high potency and improved pharmacokinetic properties [38]. However, as the field is young and the timeline from hit identification to the clinic spans more than a decade, no such inhibitor has reached the clinic so far.
Proof-of-principle for the development of small molecules has been obtained for different protein-protein interfaces (for recent reviews see $[27,28,41])$. A typical example of a novel drug target in cancer treatment is the human protein double minute 2 (HDM2) [42]. Initially, it was found that the mouse homolog of HDM2 (known as mouse protein double minute 2 [MDM2]) binds to the tumor-suppressor protein $\mathrm{p} 53$ and increases its degradation, thus blocking the transcriptional activity of $\mathrm{p} 53$ that results in tumor suppression. Inhibition of this interaction can stimulate 553 activity in cancer cells, driving them towards apoptosis [43]. X-ray crystallography of the p53-MDM2 complex revealed that this PPI is primarily mediated by a few key amino acids of p53 that form an amphipatic $\alpha$-helix and a small but deep hydrophobic cleft in MDM2 [44,45]. In the search for inhibitors, a HTS performed at F. Hoffman-La Roche (Nutley, NJ, USA) identified a group of tetra-substituted imidazoles, which can potently disrupt the MDM2-p53 interaction and were named nutlins [35]. It was observed that nutlins mimic the binding of the helical region of $\mathrm{p} 53$ by interacting with the hydrophobic cleft of MDM2. Furthermore, these compounds are active against tumor xenografts in vivo [35].

Importantly, antiviral activity of PPI inhibitors was also demonstrated with molecules targeting human papillomaviruses. These viruses need only two virally-encoded proteins, E1 and E2, for replication of their genomes. E2 is a DNAbinding protein required for transcription and replication of the viral genome, as well as its segregation during mitosis. E1 is the replicative helicase of papillomaviruses. E2 binds to the viral origin of replication and forms complexes with E1 and the viral DNA, which are essential for the viral DNA replication. The essential roles of E1 and E2 in the viral life cycle make them attractive targets for antiviral therapies. A HTS of 140,000 molecules performed at Boehringer Ingelheim (Berkshire, UK) identified one lead structure inhibiting the assembly of the E1-E2origin ternary complex. Further optimization by medicinal chemistry led to a series of compounds consisting of an indandione fused to a substituted tetrahydrofuran [37]. Characterization of their mechanism of action pointed to an interaction with the viral transcription factor E2, thereby preventing the interaction with the viral E1 helicase, necessary for viral replication [46]. $\mathrm{X}$-ray crystallography revealed that the inhibitors bind in a small-molecule binding pocket on E2 [47]. 
Very recently a paper was published showing the first SMPPII of the HIV-1 Vif-APOBEC3G (apolipoprotein B mRNA-editing enzyme catalytic polypeptide-like $3 \mathrm{G}$ ) interaction exhibiting antiviral activity. APOBEC3G was initially identified as a HIV restriction factor in target CD4 T cells [48]. During reverse transcription, APOBEC proteins carried with the incoming HIV particle into the cell deaminate $\mathrm{dC}$ to $\mathrm{dU}$ in nascent minus-strand viral DNA, resulting in G-to-A hypermutation in the plus strand DNA and leading to degradation of the viral DNA [49,50]. The HIV-1 Vif protein counteracts this enzyme in producer cells by degradation via the ubiquitin-proteasome pathway [51]. Interference with the Vif-APOBEC3G interaction, raising intracellular or virion-associated levels of APOBEC 3G, or reducing intracellular levels of Vif, all hold promise as therapeutic approaches to enhance the innate cellular antiviral activity. In fact, a first small molecule disrupting Vif-APOBEC3G interaction recently arose from a screen [52]. The compound, called $\mathrm{RN}-18$, inhibits HIV replication in the low micromolar range. The authors also show that the inhibition is Vif-specific and that RN-18 is only functional in the presence of APOBEC3G. The molecule upregulates the concentration of APOBEC3G in the cell and enhances its incorporation into HIV virions, stimulating cytidine deamination of the viral genome. This paper nicely illustrates the great potential of SMPPIIs as future antiviral drugs in HIV therapy. Still, incomplete suppression of Vif-APOBEC3G interaction holds the theoretical risk of inducing a mutator phenotype, facilitating resistance against other drugs present in the inevitable cocktails.

\section{The cofactors of HIV integrase}

Already more than 10 different cellular proteins have been reported to interact with HIV IN and/ or interfere in the integration process. These proteins are barrier-to-autointegration factor, high mobility group chromosomal protein A1, DNAdependent protein kinase, IN interactor 1 , histone acetyltransferase p300, human heat shock protein 60 , human polycomb group embryonic ectoderm development protein, uracil DNA glycosylase, Gemin2, importin-7, von HippelLindau-binding protein 1, LEDGF/p75 and TRN-SR2 (see Table I and reviews [53-56]).

Candidate IN cofactors were traditionally identified by in vitro reconstitution of enzymatic activity of salt-stripped PICs. Alternative methods are co-immunoprecipitation or yeast two-hybrid screening. Correct validation of a potential cofactor is very labour-intensive but of crucial importance to initiate further studies. Indeed, many cofactors that have been put forward were later questioned by other research groups or still await independent confirmation. At the time of writing

\begin{tabular}{|c|c|c|}
\hline $\begin{array}{l}\text { Candidate } \\
\text { cofactor }\end{array}$ & Putative function in HIV replication & Ref. \\
\hline BAF & $\begin{array}{l}\text { Compacting viral DNA, promoting formation of intact intasome structure preventing intramolecular and } \\
\text { stimulating intermolecular integration. }\end{array}$ & [109] \\
\hline DNA-PK & Role in circularization, thereby removing proapoptotic signal of free dsDNA ends. & [110] \\
\hline human EED & Stimulation of integration in vitro. & [111] \\
\hline Gemin2 & Early postentry steps. & [112] \\
\hline HMGA1 & $\begin{array}{l}\text { Stabilizing active conformation of IN by modulating DNA structure; role in HIV-1 expression (Tat-induced LTR } \\
\text { activation) by indirectly recruiting hSWI/SNF complex via ATF-3. }\end{array}$ & [113] \\
\hline hHSP60 & Protection of IN against thermal denaturation, maybe conversion of viral proteins to active state. & {$[114]$} \\
\hline Importin 7 & PIC nuclear import. & [115] \\
\hline INI1 & More evidence for postintegration role; maybe role in nuclear import of PIC and target site selection. & [116] \\
\hline LEDGF/p75 & $\begin{array}{l}\text { Stimulation of IN activity, chromosomal tethering, targeting PICs to actively transcribed regions and protection of } \\
\text { IN from proteasomal degradation. }\end{array}$ & [117] \\
\hline p300 & Post-translational acetylation of IN. & [118] \\
\hline UNG2 & Viral cDNA editing. & [119] \\
\hline VBP1 & Proteasomal degradation of IN. & [120] \\
\hline TRN-SR2 & Nuclear import of the PIC. & [18] \\
\hline
\end{tabular}


only LEDGF/p75 and TRN-SR2 are thoroughly validated IN cofactors, as it was shown by different independent research groups that HIV depends on these proteins for its replication and that IN directly interacts with these cofactors. Therefore, only these two proteins will be discussed in detail in the following section with a focus on LEDGF/p75, because the interaction between LEDGF/p75 and HIV IN is well characterized and preclinical drug discovery for SMPPIIs has been initiated.

\section{LEDGF/p75 tethers the HIV PIC to the chromosome}

An exemplary target for the potential development of a SMPPII is the interaction between viral HIV-1 IN and the cellular protein LEDGF/ p75. After its initial identification by co-immunoprecipitation in 2003 as a high affinity binding partner of HIV IN, it took several years to validate LEDGF/p75 as a genuine antiviral target [57,58]. Before a PPI becomes an attractive target for discovery and development of small molecules, the following points need to be addressed:

- The target has to be validated as important for HIV replication

- Inhibition of the specific PPI should not be associated with toxicity
- Structural information on the PPI should be available

- Identification of genuine inhibitors would provide ultimate proof-of-concept

As discussed later, we believe that the PPI between LEDGF/p75 and IN meets the above criteria and can now be considered a drugable target

\section{- Importance of LEDGF/p75 for HIV replication}

After initial identification and validation of the interaction between LEDGF/p75 and IN [59,60], a crucial role for LEDGF/p75 in HIV replication was evidenced through different mutagenesis, RNAi, transdominant and knockout studies [61-66]. LEDGF/p75 is a member of the hepatoma-derived growth factor-related protein (HRP) family, a weak co-activator of general transcription and plays an important role in protection against cellular stress [67,68]. LEDGF/ p75 is expressed from the PSIP1 gene, which also expresses a p 52 isoform of LEDGF/p75 (Figure 2B \& C). HRPs are characterized by a conserved N-terminal PWWP domain, an approximately 90- to 135 -amino acid region that is a putatively chromatin-binding fragment. LEDGF/p75 also contains an IN-binding domain (IBD) that is mapped to the C-terminal end (residues 347-429) [69,70]. The p52 isoform lacks the IBD and fails to

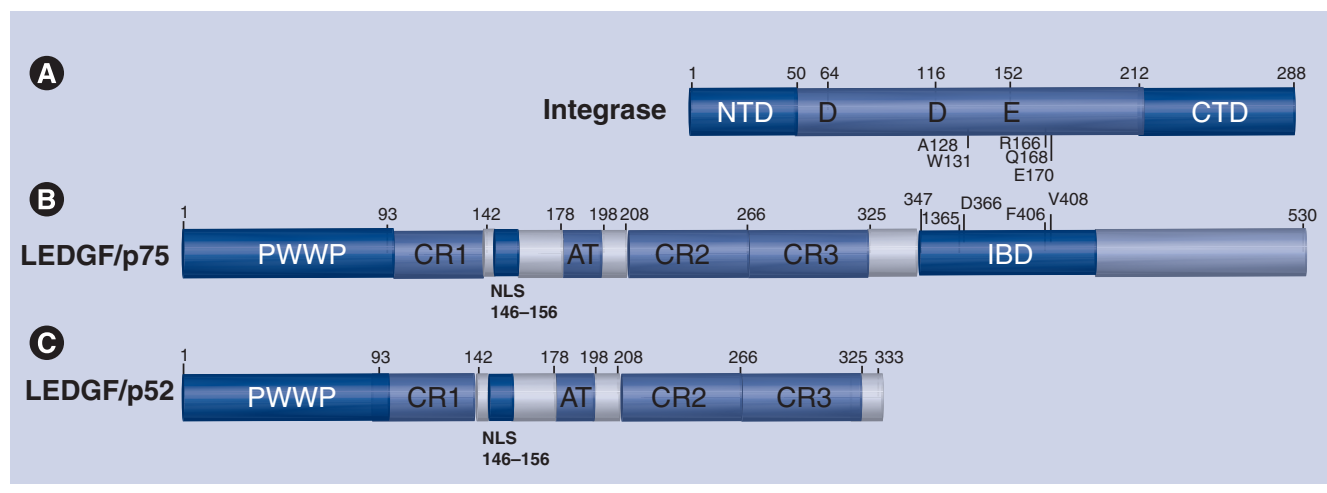

Figure 2. Domain organization of HIV-1 integrase \& LEDGF/p75. (A) Integrase consists of three distinct structural domains [121]: the N-terminal zinc-binding domain, the catalytic core containing the catalytically active DDE motif and the positively-charged CTD [122-124]. The C-terminus displays DNA-binding activity, and is (like the other two domains) involved in multimerization [125]. Amino acids in the catalytic core that are important for interaction with LEDGF/p75 are indicated [62,63,76,78] (B) The N-terminal part of LEDGF/p75, including the PWWP domain, two AT-hook motifs and CR 1 and 2, contributes to chromatin binding $[70,126,127]$. The PWWP domain most probably functions as the main chromatin tether. LEDGF/p75 has a functional nuclear localization signal [71,72]. In the C-terminal part of the protein an evolutionary conserved IBD is present [69]. (C) LEDGF/p52 is derived by alternative splicing from the PSIP1 gene $[128,129]$. The C-terminus of p52 differs in eight amino acids from its larger isoform LEDGF/p75. LEDGF/p52 lacks the IBD.

AT: A-T-rich DNA binding domain; CR: Charged regions; CTD: C-terminal domain; IBD: Integrasebinding domain; LEDGF: Lens epithelium-derived growth factor; NTD: N-terminal domain; PWWP: Proline-tryptophan-tryptophan-proline motif. 
engage HIV-1 IN in vitro or in live cells. To date, the chromatin-binding fragment is not known to be a sequence-specific DNA-binding domain. Together with other DNA-binding motifs in the N-terminal domain of LEDGF/p75, the PWWP domain is thought to direct the viral integration to transcriptionally active sites in the chromatin. The structure of LEDGF/p75 with the IBD on one end, the chromatin-binding domain on the other end and the fact that ectopically expressed IN is tethered to the chromatin by LEDGF/p75 all led to the hypothesis that LEDGF/p75 captures and guides incoming viral particles to the chromatin [59,61,71,72]. Supporting this hypothesis, analysis of integration sites in human cells depleted for LEDGF/p75, or in embryonic fibroblasts derived from LEDGF/p75- knockout mice, demonstrated a role for LEDGF/p75 during target site selection $[66,73,74]$.

A separate approach to validate $\mathrm{LEDGF} / \mathrm{p} 75$ as an important cofactor was undertaken by stably overexpressing the IBD fused to GFP. HIV-1 replication was severly inhibited at the step of integration $[65,75]$, probably because the overexpression of the IBD competes with endogenous LEDGF/p75 for binding to IN. This result provides proof-ofconcept for the LEDGF/p75-IN interaction as a novel target for antiviral therapy. Furthermore, by repeatedly passaging HIV in the cell lines overexpressing the IBD, strains that could overcome the inhibition were selected [76]. Although resistance developed, the resistant virus was severely crippled in its replication capacity. Analysis of the IN gene revealed two amino acid mutations: A128T and E170G, located at the described interface between IN and the IBD. Although LEDGF/p75 could still interact with the mutant IN, this occurred with a much lower affinity. Moreover, replication of the IBD-resistant virus was 10 -fold more sensitive to depletion of LEDGF/p75 than wild-type virus, indicating that the resistant virus remained dependent on LEDGF/p75 for its replication. Taken together, these results suggest an exclusive role of LEDGF/p75 during HIV integration. Furthermore, additional impetus for the development of small-molecule inhibitors of the LEDGF/ p75-IN interaction comes from the observation that removing LEDGF/p75 from cells seems to expose IN to rapid proteasomal degradation [77].

\section{- Structural biology of HIV integrase \& LEDGF/p75}

In accord with its ability to interact with HIV-1 IN, an evolutionary highly conserved IBD was identified in the C-terminus of LEDGF/p75 (amino acids 347-429) (Figure 2B) [69]. Next to LEDGF/p75, a HRP family member named HRP2 also contains the IBD. Structural analysis of the IBD by nuclear magnetic resonance showed a compact right-handed bundle composed of five $\alpha$-helices that is topologically similar to a pair of HEAT repeats [78].

Rational design of specific drugs targeting PPIs is greatly facilitated by structural data of the protein complex. Although a crystal structure of full-length IN or full-length LEDGF/ p75 is not available, a co-crystal of the interacting domains of IN and LEDGF/p75 [79] provides the required structural information and knowledge on the interacting residues in IN and LEDGF/p75 to embark on drug design. Confirmation of the biological relevance of the co-crystal was obtained by different mutagenesis studies [61-63,76]. The co-crystal shows that two monomers of IBD interact with a dimer of the catalytic core domain (CCD) of IN (Figure 3A). An interhelical loop of the IBD binds to a defined pocket at the interface of the two CCDs. The most critical interacting residues of the IBD are I365, D366 and F406 [79]. Based on the co-crystal, the principal structural features of IN recognized by LEDGF/p75 are the backbone conformation of residues 168-171 (located in $\alpha$-helices 4 and 5) from one monomer and a hydrophobic patch (amino acids 102, 128132) that is primarily comprised of $\alpha$-helices 1 and 3 in the second IN monomer [79] (Figure 3B). Ideally, small molecules could be designed that would enter this binding pocket in IN and prevent interaction with the cofactor.

\section{- Cellular toxicity}

When targeting a cellular protein, one needs to be concerned about cellular toxicity. In all RNAi-based knockdown experiments so far, knockdown of endogenous LEDGF/p75 has not been associated with apparent toxicity in human cell lines. LEDGF/p75 appears to be important during embryonic development, since the majority of homozygous LEDGF/ p75-knockout mice die soon after birth and the ones that survive display a range of abnormal phenotypes, compatible with defects in homeodomain proteins [80]. However, both p75 and p52 splice variants are depleted in the knockout mice, whereas an HIV therapeutic strategy would only target the PPI between IN and p75, ideally without affecting its cellular function. It is likely that LEDGF/p75 plays a pleiotropic role in both cell survival and apoptosis-mediated 


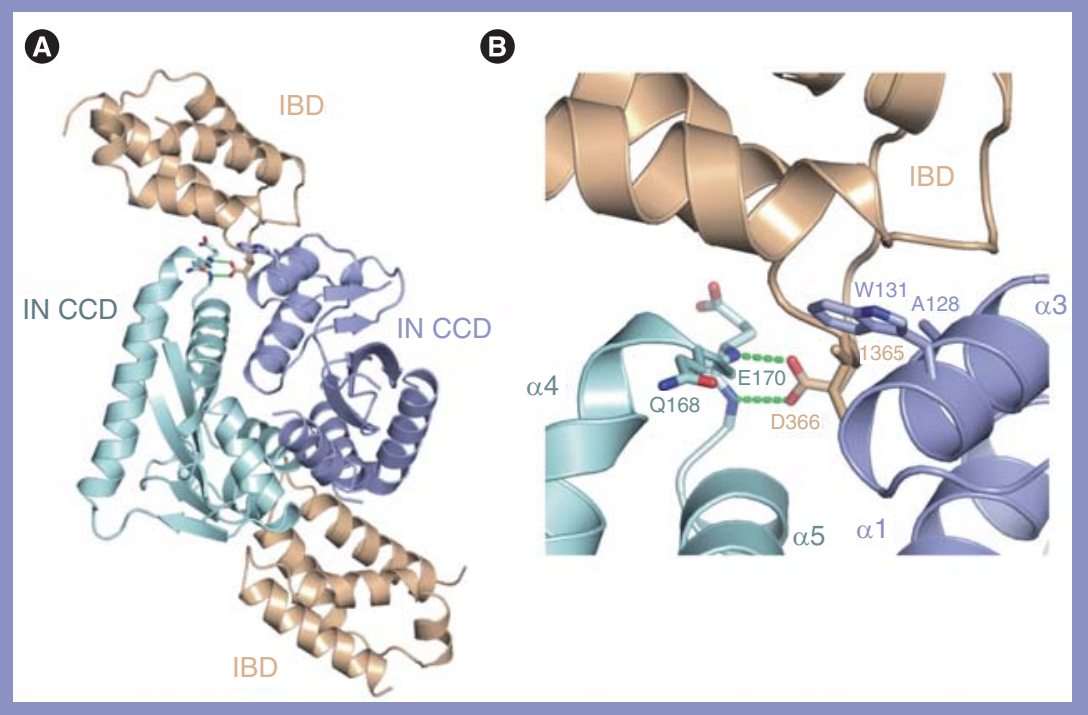

Figure 3. Structure of the HIV-1 IN CCD-IBD interface. (A) IN CCD dimer interacting with the LEDGF/p75 IBD using Protein Data Bank crystal structure file 2BJ4. (B) Close-up view of the interface. The IN CCD monomers are coloured purple and blue and the IBD subunit is brown. The selected residues are shown as sticks, and hydrogen bonds are indicated by dotted lines. The IN residues A128 and W131 of the first IN monomer (purple) are part of a hydrophobic patch, which accommodates the side chains of the LEDGF/p75 residues I365, F406 and V408. IN residues 166-171 are part of the so-called $\alpha 4 / 5$ connector-linking helices $\alpha 4$ and $\alpha 5$ of the second IN monomer (blue). LEDGF/p75 residue D366 forms hydrogen bonds with the backbone amides of IN E170 and H171.

CCD: Catalytic core domain; IBD: Integrase-binding domain; IN: Integrase; LEDGF: Lens epithelium-derived growth factor.

cell death. On the one hand it can transcriptionally activate antiapoptotic proteins in response to different kinds of stresses [68]. On the other hand LEDGF/p75 is cleaved by main effector caspases in apoptosis, resulting in two cleavage fragments, which upon overexpression abrogate the prosurvival role of LEDGF/p75 [81]. In any case, future lead compounds will have to be carefully evaluated for teratogenicity and toxicity. Valuable information in this respect will come from cell biology studies on LEDGF/p75. An ongoing effort attempts to identify its cellular binding partners. Two groups independently identified JPO2 as a first cellular binding partner of the IBD $[82,83]$. Competition assays show a mutually exclusive binding of either JPO2 or HIV-1 IN to LEDGF/p75. However, while the binding regions overlap, different mechanisms of interaction were proposed since JPO2 still interacts with LEDGF/p75 mutants that are totally defective for interaction with HIV-1 IN [83]. The finding of these differential interactions between IN, LEDGF/75 and JPO2 suggests the feasibility of developing inhibitors specifically targeting the interaction between LEDGF/p75 and HIV-1 IN.
- Proof-of-concept for the identification of genuine integrase-LEDGF/p75 inhibitors

The identification of the first small molecules that interfere with the IN-LEDGF/p75 interaction and block HIV replication will provide enormous stimulation to the field. In a recent report it was shown that an LEDGF/p75-derived peptide (amino acid 355-377) that contains two IN interacting residues (I365 and D366) could disrupt the IN-LEDGF/p75 interaction with an $\mathrm{IC}_{50}$ value of $25 \mu \mathrm{M}$ [84]. The peptide furthermore inhibits in vitro IN enzymatic activity with $\mathrm{IC}_{50}$ values of 165 and $153 \mu \mathrm{M}$ for 3'-processing and strand transfer, respectively. There are no data available as yet on antiviral activity and toxicity in cell culture. Hou et al. (Schering-Plough, Kenilworth, NJ, USA) have described the further development of an Alphascreen interaction assay that was first described by De Rijck et al. [75] as a HTS tool. A total of 700,000 compounds were analyzed and several compounds showing in vitro activity in the low micromolar range were identified [85]. It is unclear whether these compounds demonstrate antiviral activity. Du et al. recently reported a small molecular compound called D77 that potently inhibits the IN-LEDGF/p75 reaction in both yeast and mammalian two-hybrid assays and affects nuclear distribution of enhanced yellow fluorescent protein (EYFP)-IN, possibly by blocking the interaction between EYFP-IN and LEDGF/p75 [86]. D77, a benzoic acid derivative, also exhibited antiretroviral activity in MT-4 cells in the micromole range and interacts with the IN core domain in a surface plasmon resonance assay, possibly showing for the first time the feasibility of a small molecule inhibiting HIV replication by blocking the IN-LEDGF/p75 interaction. However, whether this activity can indeed be attributed to the disruption of the IN-LEDGF/ p75 interaction awaits further confirmation.

\section{TRN-SR2 mediates nuclear import of HIV into the nucleus}

Kataoka et al. originally identified a 975-amino acid importin named TRN-SR in a yeast twohybrid screen for proteins binding to the arginine/serine-rich (RS) domain of SR (serine/ arginine-rich) proteins. These proteins are essential mRNA splicing factors and are characterized by the presence of a domain containing several, often numerous, arginine/serine dipeptide repeats [87]. In the same study TRN-SR was shown to be responsible for the nuclear import of RS domain-containing fusion proteins and the binding to several SR proteins, suggesting that 
TRN-SR is a common import receptor for many of the SR proteins. Lai et al. also used a yeast two-hybrid screen to look for proteins interacting with the RS hinge region of the E2 human papillomavirus type 5 protein, and revealed an E2-binding protein, TRN-SR2, that is almost identical to the earlier described TRN-SR, which was called TRN-SR1 from then on [88]. TRN-SR 2 contains only 923 amino acids and lacks two regions of approximately 30 amino acid residues present in TRN-SR1. It also binds to several SR proteins by interaction with their phosphorylated RS domain, which is disrupted by binding of Ran-GTP [88,89]. The distribution of the transcripts encoding TRN-SR 1 and TRN-SR2, which are alternatively spliced products of the same gene, tnpo3, was examined in mammalian cells. The transcript of TRN-SR2 is predominantly expressed in most cells and tissues investigated, with a higher abundance in testis, while the TRN-SR1 isoform remained undetectable [90]. Surprisingly, in another yeast two-hybrid screen multiple non-SR-proteins were identified as binding partners of TRN-SR2. The most prominent binding partner was RNAbinding motif protein 4 , a zinc finger protein involved in regulation of splicing [91].

We identified the direct interaction between HIV-1 IN and TRN-SR2 in a yeast two-hybrid screen [19]. Moreover, siRNA- and shRNA-mediated knockdown of TRN-SR2 was found to severely inhibit HIV-1 and HIV-2 replication in both dividing and nondividing cells including primary macrophages. Transduction by a HIV-based lentiviral vector was also inhibited by TRN-SR 2 knockdown, but a murine leukemia virus-derived retroviral vector was hardly affected. Since in these experiments vector transduction was measured by cytomegalovirus promotor-driven luciferase expression, the results argue against a role for TRN-SR2 in lentiviral mRNA splicing and point to a block in an early step in the HIV life cycle. Also, TRN-SR2 bound directly to HIV-1 IN in yeast two-hybrid and pull-down experiments, but not to murine leukemia virus IN, suggesting a lentivirus-specific role for TRN-SR2 in viral replication [19]. Importantly, the knockdown of TRN-SR2 did not inhibit viral replication initiated by transfecting a plasmid encoding the viral genome, again excluding a role for TRN-SR2 in the late steps of replication. Via quantitative PCR (qPCR) analysis of DNA species in knockdown cells, a strong reduction in viral integration and a modest reduction in 2-long terminal repeat circles was detected suggesting a role in nuclear import. Finally, we employed a novel method to track fluorescently labeled virus during HIV infection [22] to corroborate a direct role of TRN-SR2 in HIV nuclear import. Together our results point to a crucial role for TRN-SR2 in nuclear import of the HIV PIC (Figure I) [19].

Interestingly, TRN-SR 2 featured among the 273 putative HIV cofactors revealed by a genome-wide RNAi screen reported while our manuscript was in preparation [18]. TRN-SR2 knockdown by eight different siRNAs was found to inhibit HIV infection in both HeLa and Jurkat cells, independent of the HIV envelope. Tat-dependent reporter gene expression was only weakly affected by TRN-SR 2 knockdown, arguing against a role for TRN-SR2 in the SR protein-dependent splicing of HIV Tat. A qPCR assay showed that the block in HIV replication occurs after reverse transcription but before integration, but no evidence for a role in nuclear import was given [18].

A second genome-wide siRNA screen to identify HIV cofactors of the early steps of the viral life cycle was recently published [20]. Again TRN-SR 2 knockdown potently inhibited HIVbased vector transduction [20]. Based on qPCR experiments König et al. proposed TRN-SR2 as a potential import factor of the HIV PIC but again no direct interaction assays with HIV IN were performed [20].

There is an increasing interest in the development of agents that target nuclear translocation pathways critical for virus replication, drug delivery of anticancer medications, improved nonviral gene transfer, and modulation of steroid receptor transport relevant to anti-inflammatory therapy [21]. Considering the important role that TRN-SR 2 seems to play in the nuclear import of HIV, and taking into account that its role in HIV replication has by now been validated by three independent research groups, we believe that the PPI between TRN-SR2 and IN is an emerging new target for developing SMPPIIs.

\section{Conclusion}

During the past years the importance of cellular cofactors for HIV replication has become more and more apparent. Similar to other viruses, HIV-1 has only a limited genetic make up $(\sim 10 \mathrm{~kb})$, although it has to carry out multiple and distinct functions. Consequently, the virus takes advantage of cellular proteins and cellular pathways to complete the different steps in its life cycle. Since these interactions between viral and 
cellular components are often based on PPIs, and interest in the development of SMPPIIs is growing rapidly, we conclude that a new era in HIV research is emerging in which pharmaceutical companies and academic researchers will focus on PPIs between HIV proteins and their cellular cofactors as new targets for antiviral therapies.

As an example of this new paradigm we discussed in detail the IN cofactor LEDGF/p75, a tethering factor for the HIV PIC for which validation is completed and drug development is ongoing.

Based on the lessons learnt from the studies on the IN-LEDGF/p75 interaction, we would like to put forward the following requirements for the validation of any new HIV cofactor as an anti-HIV target:

- The cellular protein functions as a cofactor rather than as a restriction factor

- The cofactor is unique - no alternative pathways are exploited by HIV

- Structural information on the interface is available

- The role of the cofactor during HIV replication differs from its role in normal cell metabolism

- The viral part of the interface is genetically conserved

However, there are some exceptions to these requirements. For example, in some specific cases the interaction between viral components and cellular restriction factors rather than cofactors could also be used as an antiviral target, especially when the restriction factor is not able to exert its innate antiviral function because of rescue mechanisms used by the virus. As discussed above, the Vif-APOBEC3G interaction, where the cellular restriction factor $\mathrm{APOBEC} 3 \mathrm{G}$ is targeted for proteasomal degradation by HIV-1 Vif, is a good example of this principle [52]. In this situation, targeting the interaction between the inhibitory viral component and the cellular restriction factor using small molecules could activate the innate antiviral activity of the restriction factor.

With regards to TRN-SR2, a pathway comparable to the one for LEDGF/p75 should be followed to study its potential as a new anti-HIV target. The initial validation of TRN-SR2 as a cofactor of HIV has been published and is already generally accepted in the field. However, further research is needed to elucidate the interacting domains of IN and TRN-SR2, and more in particular to identify the interaction hotspot of both binding partners, which ideally should be genetically conserved in the virus and structurally accessible for small-molecule inhibitors. In parallel we should determine whether or not a small-molecule mediated inhibition of the binding of IN to TRN-SR2 will interfere with the normal cellular function of TRN-SR 2 and cause cellular toxicity effects. For the rational design of such a SMPPII, a co-crystal of both proteins would provide invaluable structural data. A high-throughput protein-protein binding assay could be developed to screen for SMPPIIs, and initial hits must be tested in viral replication assays in cells. Promising hits should then be optimized into lead compounds in collaboration with pharmaceutical companies.

The continuous identification and validation of cellular interaction partners in HIV replication opens new opportunities for antiviral drug development. Antiviral resistance will be hindered if the number of mutations required to escape inhibitory pressure is high and if residual replication is hampered by reduced fitness of the resistant strains. The conserved nature of the cellular cofactor and its interaction site with IN suggest a high genetic barrier to resistance. Although the primary goal of anti-HIV therapy is to reduce HIV replication in the patient so as to prevent further disease progression, the ultimate goal of reducing HIV replication beyond the limit of drug resistance may eventually come within reach.

\section{Future perspectives: potential new targets for SMPPIIs inhibiting HIV infection}

The expanding knowledge about the function of cellular proteins in (retro)viral replication has opened a new field of research in virology. Novel methods to identify and validate new cofactors have been introduced, resulting in an exponential increase in the number of identified cellular cofactors and restriction factors $[18,53,55,92]$. Proteomic-based approaches can identify cellular proteins physically interacting with viral proteins and include co-immunoprecipitation and analysis of virion-associated proteins by mass spectrometry. Genomic screening techniques like yeast two-hybrid can also be used to identify direct interaction partners of viral proteins. Recently, functional genomic screens have emerged as a valuable tool for high-throughput identification of individual players in a pathway of interest. Using large-scale siRNA screens, Brass et al. and König et al. were able to identify 273 and 295 
cellular proteins HIV depends on for its replication, respectively $[18,20]$. However, care must be taken because further analysis is definitely required to validate these cofactors and evaluate their potential as future anti-HIV drug targets.

A proof-of-principle for PPIs between HIV and cellular proteins as drugable targets is given by the emergence of a new class of HIV inhibitors on the market, namely enfuvirtide and maraviroc. These molecules are classified as HIV entry inhibitors. Although enfuvirtide and maraviroc are not PPI inhibitors pur sang, since they interfere with ligand-receptor interactions, these therapeutics illustrate the great potential of blocking the interaction between viral and cellular proteins for antiviral therapy. Enfuvirtide (T20, Fuzeon $^{\mathrm{TM}}$ ) binds to the viral gp41 protein and inhibits the conformational changes needed for fusion of the virus and cell membrane. Therefore, it is also referred to as a fusion inhibitor [93]. In September 2007, maraviroc (Celsentri ${ }^{\mathrm{TM}}$ ) was approved by the US FDA as an entry inhibitor and chemokine receptor antagonist. This small-molecule inhibitor specifically blocks the chemokine receptor CCR5, preventing its interaction with gp120 [94]. Other HIV entry inhibitors, such as monoclonal antibodies and small molecules, are being developed and analyzed in clinical trials (for a review see [95]).

Several other PPIs involved in different stages of the HIV-1 replication cycle are currently investigated for their therapeutic potential. As discussed above, the CypA-CA interaction promotes an early step in HIV replication and is therefore an attractive target for new therapeutic strategies. Several classes of compounds are currently under investigation:

- Compounds that specifically block CA protein formation

- Compounds that bind to the capsid and inhibit its assembly

- Compounds that bind CypA and possibly inhibit capsid disassembly [96]

As discussed earlier, it was shown that the VifAPOBEC3G interaction can be used as an antiviral target [52]. Still, there is the theoretical risk of incomplete suppression of the Vif-APOBEC3G interaction, which could induce a mutator phenotype facilitating resistance development against other drugs.

Much like other retroviruses, HIV employs the cellular cytoskeleton for its transport from the plasma membrane through the cytoplasm into the nucleus. As mentioned above, little is known about the retroviral proteins mediating the interactions with the cytoskeleton. While earlier studies indicated direct interactions of retroviral proteins with the host cytoskeleton, more recent screens have identified several host cytoskeletal regulatory factors involved in intracellular trafficking of various retroviruses including HIV-1. This growing list of host/viral cytoskeletal regulatory proteins suggests that more factors await identification [7]. Further research is mandatory to disclose new drugable PPIs in this expanding field.

It is possible that virus assembly, budding and the release of viral particles require the most cellular cofactors (reviewed in [92]). The most promising targets for drug discovery are CD137 (a membrane protein called tetherin) [97], tail-interacting protein of $47 \mathrm{kDa}$ (TIP47) [98] and Tsg101 [99,100]. The release and spread of retroviruses is inhibited in certain cell types by the host protein, tetherins. Tetherins are counteracted by the action of the HIV-1 Vpu protein [97]. Although no direct PPI between Vpu and tetherin was demonstrated, better understanding of the mechanism of action of tetherin and the way by which Vpu circumvents tetherin-mediated restriction could lead to strategies limiting the spread of HIV-1. The host protein TIP47 is involved in virion assembly. The protein not only interacts with viral Env, but also binds to the matrix domain of HIV-1 Gag, resulting in ternary complex formation [98,101]. TIP47 is a cofactor that plays an essential role in Env incorporation, allowing HIV-1 Gag and Env proteins to encounter each other and physically associate during the viral assembly process, and could therefore be considered as a target for drug discovery [98].

Retrovirus budding also requires the host machinery, namely endosomal complexes referred to as endosomal sorting complex required for transport (ESCRTs). In infected cells, Gag redirects the ESCRT machinery to the plasma membrane for budding out of the cell. This process involves the contact of viral Gag with many of the ESCRTs, for example, interaction with Tsg101 through the Gag PTAP motif $[102,103]$. Furthermore, it was demonstrated that this requirement for the Gag-Tsg101 interaction is necessary for HIV-1 release [99,100]. Although blocking essential interactions between Gag and host proteins constitutes an innovative strategy for impairing the production of infectious viruses and the spreading of HIV-1, 
drug development is jeopardized by toxicity. As sorting and trafficking of viral proteins is undistinguishable from normal cellular processes, it might be difficult to find a nontoxic inhibitor targeting these steps.

A different therapeutic strategy is represented by inhibitors of the dimerization of HIV IN, reverse transcriptase or protease [104-108]. Although these protein interfaces are promising alternative targets for HIV drug discovery involving SMPPIIs and could validate the potential of SMPPIIs, resistance against dimerization inhibitors and/or cross-resistance against existing IN, reverse transcriptase and protease inhibitors will most likely develop rapidly, since only viral proteins are targeted.

The alternative virus-host interactions briefly discussed together highlight the potentially broad applicability of developing SMPPIIs as antiviral agents. The interactions between the proteins of HIV and their cellular binding partners are thus valid targets for future drug therapy that merit increasing attention of academic and industrial scientists.

\section{Financial \& competing interests disclosure} We are financially supported by grants from the FWO (G.0530.08) and FP7 (THINC, Health-20072002.3.2-1) programs and the CellCoVir SBO project of the IWT. W Thys is supported by a grant from the Institute for the Promotion of Innovation through Science and Technology in Flanders (IWT-Vlaanderen). The authors have no other relevant affiliations or financial involvement with any organization or entity with a financial interest in or financial conflict with the subject matter or materials discussed in the manuscript apart from those disclosed.

No writing assistance was utilized in the production of this manuscript.

\section{Executive summary}

\section{Early steps of the HIV replication cycle}

- HIV enters the cell by binding to the CD4 receptor. After uncoating and initiation of reverse transcription the reverse transcription complex (RTC) uses the cytoskeleton to travel to the nuclear membrane.

- Importins mediate import of macromolecules by crossing the nuclear pore complex through the nuclear membrane into the nucleus. Until recently, it was unclear which cellular protein imports the HIV pre-integration complex (PIC).

- After nuclear import, HIV integrase (IN) stably inserts the viral DNA into the host cell chromosome in a multistep process called integration.

\section{Protein-protein interactions \& drug development}

- Protein-protein interactions (PPIs) represent a large and important class of therapeutic targets. The most attractive class of inhibitors consists of small-molecule PPI inhibitors (SMPPIIs), but the identification or design of SMPPIls is considerably more difficult than the development of inhibitors of classical targets like active sites of enzymes or ligand-binding pockets.

- Characteristic PPI interfaces are often large, flat and adaptive and do not bind small ligands that could serve as a template for the design of SMPPIls. Available libraries of small molecules are typically designed for classical targets.

- More and more recent publications report proof-of-principle molecules that block PPIs, some of them displaying antiviral activity.

\section{Lens epithelium-derived growth factor/p75 tethers the HIV pre-integration complex to the chromosome}

- A crucial role for lens epithelium-derived growth factor LEDGF/p75 in HIV replication was evidenced through different approaches based on mutagenesis, RNAi, transdominant inhibition and knockout mice.

- Inhibition of HIV replication by overexpression of the IN-binding domain revealed an exclusive role for LEDGF/p75 during HIV integration and provided proof-of-concept for the LEDGF/p75-IN interaction as a novel target for antiviral therapy.

- A co-crystal of the interacting domains of IN and LEDGF/p75 provides the required structural information and knowledge on the interacting residues in IN and LEDGF/p75 to embark on drug design.

- Knockdown of endogenous LEDGF/p75 has not been associated with apparent toxicity in human cell lines, however, careful monitoring of the cellular function of LEDGF/p75 is needed during drug development.

- The first reports on molecules inhibiting the IN-LEDGF/p75 reaction have emerged

\section{Transportin-SR2 mediates nuclear import of HIV into the nucleus}

- Transportin-SR2 (TRN-SR2) imports serine- and arginine-rich proteins into the nucleus.

- It was found by three independent research groups that siRNA-mediated knockdown of TRN-SR2 inhibits HIV replication by blocking an early step in the viral life cycle in a lentivirus-specific manner.

- TRN-SR2 binds to HIV IN and imports the PIC into the nucleus.

\section{Conclusion}

" A new era in HIV research is emerging in which pharmaceutical companies and academic researchers will focus on PPIs between HIV proteins and their cellular cofactors as new targets for antiviral therapies.

- An example of this new paradigm is the IN cofactor LEDGF/p75, a tethering factor for the PIC for which validation is completed and drug development is under way.

- Regarding TRN-SR2, a research and development pathway comparable to the one for LEDGF/p75 should be followed to study its potential as a new anti-HIV target. 


\section{Bibliography}

Papers of special note have been highlighted as:

- of interest

" " of considerable interest

1 Zhang H, Dornadula G, Orenstein J, Pomerantz RJ: Morphologic changes in human immunodeficiency virus type 1 virions secondary to intravirion reverse transcription: evidence indicating that reverse transcription may not take place within the intact viral core. J. Hum. Virol. 3, 165-172 (2000).

2 McDonald D, Vodicka MA, Lucero G et al.: Visualization of the intracellular behavior of HIV in living cells. J. Cell. Biol. 159, 441-452 (2002).

3 Sokolskaja E, Luban J: Cyclophilin, TRIM5, and innate immunity to HIV-1. Curr. Opin. Microbiol. 9, 404-408 (2006).

4 Sokolskaja E, Sayah DM, Luban J: Target cell cyclophilin A modulates human immunodeficiency virus type 1 infectivity. J. Virol. 78, 12800-12808 (2004).

5 Miller MD, Farnet CM, Bushman FD: Human immunodeficiency virus type 1 preintegration complexes: studies of organization and composition. J. Virol. 71, 5382-5390 (1997).

6 Bukrinskaya A, Brichacek B, Mann A, Stevenson M: Establishment of a functional human immunodeficiency virus type 1 (HIV-1) reverse transcription complex involves the cytoskeleton. J. Exp. Med. 188, 2113-2125 (1998)

7 Naghavi MH, Goff SP: Retroviral proteins that interact with the host cell cytoskeleton. Curr. Opin. Immunol. 19, 402-407 (2007).

8 Nisole S, Saib A: Early steps of retrovirus replicative cycle. Retrovirology 1, 9 (2004).

9 Beck M, Forster F, Ecke M et al.: Nuclear pore complex structure and dynamics revealed by cryoelectron tomography. Science 306, 1387-1390 (2004).

10 Keminer O, Peters R: Permeability of single nuclear pores. Biophys. J. 77, 217-228 (1999).

11 Stewart M: Molecular mechanism of the nuclear protein import cycle. Nat. Rev. Mol. Cell. Biol. 8, 195-208 (2007).

12 De Rijck J, Vandekerckhove L, Christ F, Debyser Z: Lentiviral nuclear import: a complex interplay between virus and host. Bioessays 29, 441-451 (2007).

13 De Rijck J, Debyser Z: The central DNA flap of the human immunodeficiency virus type 1 is important for viral replication. Biochem. Biophys. Res. Commun. 349, 1100-1110 (2006).
14 De Rijck J, van Maele B, Debyser Z: Positional effects of the central DNA flap in HIV-1-derived lentiviral vectors. Biochem. Biophys. Res. Commun. 328, 987-994 (2005).

15 van Maele B, De Rijck J, De Clercq E, Debyser Z: Impact of the central polypurine tract on the kinetics of human immunodeficiency virus type 1 vector transduction. J. Virol. 77, 4685-4694 (2003).

16 Zennou V, Petit C, Guetard D, Nerhbass U, Montagnier L, Charneau P: HIV-1 genome nuclear import is mediated by a central DNA flap. Cell 101, 173-185 (2000).

17 Piller SC, Caly L, Jans DA: Nuclear import of the preintegration complex (PIC): the Achilles heel of HIV? Curr. Drug Targets 4, 409-429 (2003).

18 Brass AL, Dykxhoorn DM, Benita Y et al.: Identification of host proteins required for HIV infection through a functional genomic screen. Science 319, 921-926 (2008).

- Functional genomic screen that identified transportin-SR2 (TRN-SR2) as a cofactor of HIV replication.

19 Christ F, Thys W, De Rijck J et al.: Transportin-SR2 imports HIV into the nucleus. Curr. Biol. 18, 1192-1202 (2008).

"- First description of TRN-SR2 as a cofactor of HIV integrase and nuclear import factor of HIV.

20 Konig R, Zhou Y, Elleder D et al:: Global analysis of host-pathogen interactions that regulate early-stage HIV-1 replication. Cell 135, 49-60 (2008).

- Functional genomic screen that identified TRN-SR2 as a cofactor of HIV replication.

21 Faustino RS, Nelson TJ, Terzic A, PerezTerzic C: Nuclear transport: target for therapy. Clin. Pharmacol. Ther. 81, 880-886 (2007).

22 Albanese A, Arosio D, Terreni M, Cereseto A HIV-1 preintegration complexes selectively target decondensed chromatin in the nuclear periphery. PLoS ONE 3(6), e2413 (2008).

23 Arhel N, Genovesio A, Kim KA et al.: Quantitative four-dimensional tracking of cytoplasmic and nuclear HIV-1 complexes. Nat. Methods 3, 817-824 (2006).

24 Engelman A, Mizuuchi K, Craigie R: HIV-1 DNA integration: mechanism of viral DNA cleavage and DNA strand transfer. Cell 67, 1211-1221 (1991).

25 Yoder KE, Bushman FD: Repair of gaps in retroviral DNA integration intermediates. J. Virol. 74, 11191-11200 (2000).

26 Ryan DP, Matthews JM: Protein-protein interactions in human disease. Curr. Opin Struct. Biol. 15, 441-446 (2005).
27 Arkin MR, Wells JA: Small-molecule inhibitors of protein-protein interactions: progressing towards the dream. Nat. Rev. Drug Discov. 3, 301-317 (2004).

28 Berg T: Modulation of protein-protein interactions with small organic molecules. Angew. Chem. Int. Ed. Engl. 42, 2462-2481 (2003).

29 Lo Conte L, Chothia C, Janin J: The atomic structure of protein-protein recognition sites. J. Mol. Biol. 285, 2177-2198 (1999).

30 Clackson T, Wells JA: A hot spot of binding energy in a hormone-receptor interface. Science 267, 383-386 (1995).

31 Bogan AA, Thorn KS: Anatomy of hot spots in protein interfaces. J. Mol. Biol. 280, 1-9 (1998)

32 DeLano WL, Ultsch MH, de Vos AM, Wells JA: Convergent solutions to binding at a protein-protein interface. Science 287 , 1279-1283 (2000).

33 Luque I, Freire E: Structural stability of binding sites: consequences for binding affinity and allosteric effects. Proteins (Suppl. 4), 63-71 (2000).

34 Teague SJ: Implications of protein flexibility for drug discovery. Nat. Rev. Drug Discov. 2, 527-541 (2003).

35 Vassilev LT, Vu BT, Graves B et al.: In vivo activation of the $\mathrm{p} 53$ pathway by smallmolecule antagonists of MDM2. Science 303 844-848 (2004).

- Text book example of the development of a small-molecule protein-protein interaction inhibitor (SMPPII).

36 Grasberger BL, Lu T, Schubert C et al: Discovery and cocrystal structure of benzodiazepinedione HDM2 antagonists that activate $\mathrm{p} 53$ in cells. J. Med. Chem. 48, 909-912 (2005).

37 Yoakim C, Ogilvie WW, Goudreau N et al. Discovery of the first series of inhibitors of human papillomavirus type 11: inhibition of the assembly of the E1-E2-Origin DNA complex. Bioorg. Med. Chem. Lett. 13, 2539-2541 (2003).

38 Braisted AC, Oslob JD, Delano WL et al.: Discovery of a potent small molecule IL-2 inhibitor through fragment assembly. J. Am. Chem. Soc. 125, 3714-3715 (2003).

39 Oltersdorf T, Elmore SW, Shoemaker AR et al:: An inhibitor of Bcl-2 family proteins induces regression of solid tumors. Nature 435, 677-681 (2005).

40 Erlanson DA, McDowell RS, O'Brien T: Fragment-based drug discovery. J. Med. Chem. 47, 3463-3482 (2004). 
41 Wells JA, McClendon CL: Reaching for high-hanging fruit in drug discovery at protein-protein interfaces. Nature 450 , 1001-1009 (2007).

42 Vassilev LT: MDM2 inhibitors for cancer therapy. Trends Mol. Med. 13, 23-31 (2007).

43 Chene P, Fuchs J, Bohn J, Garcia-Echeverria C, Furet P, Fabbro D: A small synthetic peptide, which inhibits the p53-hdm2 interaction, stimulates the p 53 pathway in tumor cell lines. J. Mol. Biol. 299, 245-253 (2000).

44 Chi SW, Lee SH, Kim DH et al:: Structural details on mdm2-p53 interaction. J. Biol. Chem. 280, 38795-38802 (2005).

45 Kussie PH, Gorina S, Marechal V et al.: Structure of the MDM2 oncoprotein bound to the p53 tumor suppressor transactivation domain. Science 274, 948-953 (1996).

46 White PW, Titolo S, Brault K et al.: Inhibition of human papillomavirus DNA replication by small molecule antagonists of the E1-E2 protein interaction. J. Biol. Chem. 278, 26765-26772 (2003).

47 Wang Y, Coulombe R, Cameron DR et al.: Crystal structure of the E2 transactivation domain of human papillomavirus type 11 bound to a protein interaction inhibitor. J. Biol. Chem. 279, 6976-6985 (2004).

48 Sheehy AM, Gaddis NC, Choi JD, Malim MH: Isolation of a human gene that inhibits HIV-1 infection and is suppressed by the viral Vif protein. Nature 418, 646-650 (2002).

49 Lecossier D, Bouchonnet F, Clavel F, Hance AJ: Hypermutation of HIV-1 DNA in the absence of the Vif protein. Science 300, 1112 (2003).

50 Mangeat B, Turelli P, Caron G, Friedli M, Perrin L, Trono D: Broad antiretroviral defence by human APOBEC3G through lethal editing of nascent reverse transcripts. Nature 424, 99-103 (2003)

51 Sheehy AM, Gaddis NC, Malim MH: The antiretroviral enzyme APOBEC $3 \mathrm{G}$ is degraded by the proteasome in response to HIV-1 Vif. Nat. Med. 9, 1404-1407 (2003).

52 Nathans R, Cao H, Sharova N et al.: Small-molecule inhibition of HIV-1 Vif. Nat. Biotechnol. 26, 1187-1192 (2008).

- First report on a small-molecule inhibitor of the interaction between Vif and apolipoprotein B mRNA-editing enzyme catalytic polypeptide-like 3G (APOBEC3G) causing hypermutation of the viral genome.

53 van Maele B, Busschots K, Vandekerckhove L, Christ F, Debyser Z: Cellular co-factors of HIV-1 integration. Trends Biochem. Sci. 31, 98-105 (2006).
54 van Maele B, Debyser Z: HIV-1 integration: an interplay between HIV-1 integrase, cellular and viral proteins. AIDS Rev. 7, 26-43 (2005).

55 Al-Mawsawi LQ, Neamati N: Blocking interactions between HIV-1 integrase and cellular cofactors: an emerging antiretroviral strategy. Trends Pharmacol. Sci. 28, 526-535 (2007).

56 Turlure F, Devroe E, Silver PA, Engelman A: Human cell proteins and human immunodeficiency virus DNA integration. Front. Biosci. 9, 3187-3208 (2004).

57 Poeschla EM: Integrase, LEDGF/p75 and HIV replication. Cell. Mol. Life Sci. 65, 1403-1424 (2008).

58 Engelman A, Cherepanov P: The lentiviral integrase binding protein LEDGF/p75 and HIV-1 replication. PLoS Pathog. 4(3), e1000046 (2008).

59 Maertens G, Cherepanov P, Pluymers W et al.: LEDGF/p75 is essential for nuclear and chromosomal targeting of HIV-1 integrase in human cells. J. Biol. Chem. 278, 3352833539 (2003).

60 Llano M, Vanegas M, Fregoso O et al.: LEDGF/p75 determines cellular trafficking of diverse lentiviral but not murine oncoretroviral integrase proteins and is a component of functional lentiviral preintegration complexes. J. Virol. 78, 9524-9537. (2004).

61 Emiliani S, Mousnier A, Busschots K et al: Integrase mutants defective for interaction with LEDGF/p75 are impaired in chromosome tethering and HIV-1 replication. J. Biol. Chem. 280, 25517-25523 (2005).

62 Busschots K, Voet A, De Maeyer M et al.: Identification of the LEDGF/p75 binding site in HIV-1 integrase. J. Mol. Biol. 365, 1480-1492 (2007).

63 Rahman S, Lu R, Vandegraaff N, Cherepanov $P$, Engelman A: Structure-based mutagenesis of the integrase-LEDGF/p75 interface uncouples a strict correlation between in vitro protein binding and HIV-1 fitness. Virology 357, 79-90 (2007).

64 Vandekerckhove L, Christ F, van Maele B et al.: Transient and stable knockdown of the integrase cofactor LEDGF/p75 reveals its role in the replication cycle of human immunodeficiency virus. J. Virol. 80, 1886-1896 (2006).

65 Llano M, Saenz DT, Meehan A et al.: An essential role for LEDGF/p75 in HIV integration. Science 314, 461-464 (2006).

66 Marshall HM, Ronen K, Berry C et al.: Role of PSIP1/LEDGF/p75 in lentiviral infectivity and integration targeting. PLoS ONE 2(12), e1340 (2007).
67 Singh DP, Fatma N, Kimura A, Chylack LT Jr, Shinohara T: LEDGF binds to heat shock and stress-related element to activate the expression of stress-related genes. Biochem. Biophys. Res. Commun. 283, 943-955 (2001).

68 Shinohara T, Singh DP, Fatma N: LEDGF, a survival factor, activates stress-related genes. Prog. Retin. Eye Res. 21, 341-358 (2002).

69 Cherepanov P, Devroe E, Silver PA, Engelman A: Identification of an evolutionarily conserved domain in human lens epithelium-derived growth factor/ transcriptional co-activator p75 (LEDGF/ p75) that binds HIV-1 integrase. J. Biol. Chem. 279, 48883-48892 (2004).

70 Llano M, Vanegas M, Hutchins N Thompson D, Delgado S, Poeschla EM: Identification and characterization of the chromatin-binding domains of the HIV-1 integrase interactor LEDGF/p75. J. Mol. Biol. 360, 760-773 (2006).

71 Vanegas M, Llano M, Delgado S, Thompson D, Peretz M, Poeschla E: Identification of the LEDGF/p75 HIV-1 integrase-interaction domain and NLS reveals NLS-independent chromatin tethering. J. Cell Sci. 118, 1733-1743 (2005).

72 Maertens G, Cherepanov P, Debyser Z, Engelborghs $Y$, Engelman A: Identification and characterization of a functional nuclear localization signal in the HIV-1 integrase interactor LEDGF/p75. J. Biol. Chem. 279, 33421-33429 (2004).

73 Ciuffi A, Llano M, Poeschla E et al.: A role for LEDGF/p75 in targeting HIV DNA integration. Nat. Med. 11, 1287-1289 (2005).

74 Shun MC, Raghavendra NK, Vandegraaff N et al: : LEDGF/p75 functions downstream from preintegration complex formation to effect gene-specific HIV-1 integration. Genes Dev. 21, 1767-1778 (2007).

75 De Rijck J, Vandekerckhove L, Gijsbers R et al:: Overexpression of the lens epitheliumderived growth factor/p75 integrase binding domain inhibits human immunodeficiency virus replication. J. Virol. 80, 11498-11509 (2006).

- Describes the transdominant inhibition of HIV replication by overexpression of the integrase-binding domain of LEDGF/p 75 , which provided proof-of-principle that the interaction between integrase and LEDGF/ p75 is a drugable antiviral target.

76 Hombrouck A, De Rijck J, Hendrix J et al. Virus evolution reveals an exclusive role for LEDGF/p75 in chromosomal tethering of HIV. PLoS Pathog. 3, e47 (2007) 
77 Llano M, Delgado S, Vanegas M, Poeschla EM: Lens epithelium-derived growth factor/p75 prevents proteasomal degradation of HIV-1 integrase. J. Biol. Chem. 279, 55570-55577 (2004).

78 Cherepanov P, Sun ZY, Rahman S, Maertens G, Wagner G, Engelman A: Solution structure of the HIV-1 integrasebinding domain in LEDGF/p75. Nat. Struct. Mol. Biol. 12, 526-532 (2005).

79 Cherepanov P, Ambrosio AL, Rahman S, Ellenberger T, Engelman A: Structural basis for the recognition between HIV-1 integrase and transcriptional coactivator $\mathrm{p} 75$. Proc. Natl Acad. Sci. USA 102, 17308-17313 (2005).

80 Sutherland HG, Newton K, Brownstein DG et al:: Disruption of LEDGF/PSIP1 results in perinatal mortality and homeotic skeletal transformations. Mol. Cell. Biol. 26, 7201-7210 (2006).

81 Wu X, Daniels T, Molinaro C, Lilly MB, Casiano CA: Caspase cleavage of the nuclear autoantigen LEDGF/p75 abrogates its pro-survival function: implications for autoimmunity in atopic disorders. Cell Death Differ. 9, 915-925 (2002).

82 Maertens GN, Cherepanov P, Engelman A: Transcriptional co-activator $\mathrm{p} 75$ binds and tethers the Myc-interacting protein JPO2 to chromatin. J. Cell Sci. 119, 2563-2571 (2006).

83 Bartholomeeusen K, De Rijck J, Busschots K et al: Differential interaction of HIV-1 integrase and JPO2 with the $\mathrm{C}$ terminus of LEDGF/p75. J. Mol. Biol. 372, 407-421 (2007).

84 Al-Mawsawi LQ, Christ F, Dayam R, Debyser $\mathrm{Z}$, Neamati N: Inhibitory profile of a LEDGF/p75 peptide against HIV-1 integrase: insight into integrase-DNA complex formation and catalysis. FEBS Lett. 582(10), 1425-1430 (2008).

85 Hou Y, McGuinness DE, Prongay AJ et al.: Screening for antiviral inhibitors of the HIV integrase-LEDGF/p75 interaction using the AlphaScreen luminescent proximity assay. J. Biomol. Screen. 13, 406-414 (2008).

86 Du L, Zhao Y, Chen J et al.: D77, one benzoic acid derivative, functions as a novel anti-HIV-1 inhibitor targeting the interaction between integrase and cellular LEDGF/p75. Biochem. Biophys. Res. Commun. 375, 139-144 (2008).

87 Kataoka N, Bachorik JL, Dreyfuss G: Transportin-SR, a nuclear import receptor for SR proteins. J. Cell. Biol. 145, 1145-1152 (1999).

88 Lai MC, Lin RI, Huang SY, Tsai CW, Tarn WY: A human importin- $\beta$ family protein, transportin-SR2, interacts with the phosphorylated RS domain of SR proteins. J. Biol. Chem. 275, 7950-7957 (2000).
89 Lai MC, Lin RI, Tarn WY: Transportin-SR2 mediates nuclear import of phosphorylated SR proteins. Proc. Natl Acad. Sci. USA 98, 10154-10159 (2001).

90 Yun CY, Velazquez-Dones AL, Lyman SK, Fu XD: Phosphorylation-dependent and -independent nuclear import of RS domain-containing splicing factors and regulators. J. Biol. Chem. 278, 18050-18055 (2003).

91 Lai MC, Kuo HW, Chang WC, Tarn WY: A novel splicing regulator shares a nuclear import pathway with SR proteins. EMBO J. 22, 1359-1369 (2003).

92 Goff SP: Host factors exploited by retroviruses. Nat. Rev. Microbiol. 5, 253-263 (2007).

93 Kilby JM, Hopkins S, Venetta TM et al: : Potent suppression of HIV-1 replication in humans by T-20, a peptide inhibitor of gp41-mediated virus entry. Nat. Med. 4 , 1302-1307 (1998).

94 Dorr P, Westby M, Dobbs S et al.: Maraviroc (UK-427,857), a potent, orally bioavailable, and selective small-molecule inhibitor of chemokine receptor CCR5 with broadspectrum antihuman immunodeficiency virus type 1 activity. Antimicrob. Agents Chemother. 49, 4721-4732 (2005).

- Highlights maraviroc as the first proteinprotein interaction inhibitor with antiviral activity against HIV-1.

95 Agrawal L, Lu X, Jin Q, Alkhatib G: Anti-HIV therapy: current and future directions. Curr. Pharm. Des. 12, 2031-2055 (2006).

96 Li J, Tang S, Hewlett I, Yang M: HIV-1 capsid protein and cyclophilin a as new targets for anti-AIDS therapeutic agents. Infect. Disord. Drug Targets 7, 238-244 (2007).

97 Neil SJ, Zang T, Bieniasz PD: Tetherin inhibits retrovirus release and is antagonized by HIV-1 Vpu. Nature 451, 425-430 (2008).

98 Lopez-Verges S, Camus G, Blot G, Beauvoir R, Benarous R, Berlioz-Torrent C: Tail-interacting protein TIP47 is a connector between Gag and Env and is required for Env incorporation into HIV-1 virions. Proc. Natl Acad. Sci. USA 103, 14947-14952 (2006).

99 Martin-Serrano J, Zang T, Bieniasz PD: HIV-1 and Ebola virus encode small peptide motifs that recruit Tsg101 to sites of particle assembly to facilitate egress. Nat. Med. 7 , 1313-1319 (2001).

100 Demirov DG, Ono A, Orenstein JM, Freed EO: Overexpression of the $\mathrm{N}$-terminal domain of TSG101 inhibits HIV-1 budding by blocking late domain function. Proc. Natl Acad. Sci. USA 99, 955-960 (2002).
101 Blot G, Janvier K, Panse Le S, Benarous R, Berlioz-Torrent $\mathrm{C}$ : Targeting of the human immunodeficiency virus type 1 envelope to the trans-Golgi network through binding to TIP47 is required for env incorporation into virions and infectivity. J. Virol. 77, 6931-6945 (2003).

102 VerPlank L, Bouamr F, LaGrassa TJ et al.: Tsg101, a homologue of ubiquitin-conjugating (E2) enzymes, binds the L domain in HIV type 1 Pr55(Gag). Proc. Natl Acad. Sci. USA 98, 7724-7729 (2001).

103 Garrus JE, von Schwedler UK, Pornillos OW et al:: Tsg101 and the vacuolar protein sorting pathway are essential for HIV-1 budding. Cell 107, 55-65 (2001).

104 Molteni V, Greenwald J, Rhodes D et al.: Identification of a small-molecule binding site at the dimer interface of the HIV integrase catalytic domain. Acta Crystallogr. D Biol. Crystallogr. 57, 536-544 (2001).

105 Al-Mawsawi LQ, Fikkert V, Dayam R et al.: Discovery of a small-molecule HIV-1 integrase inhibitor-binding site. Proc. Natl Acad. Sci. USA 103, 10080-10085 (2006).

106 Hayouka Z, Rosenbluh J, Levin A et al.: Inhibiting HIV-1 integrase by shifting its oligomerization equilibrium. Proc. Natl Acad. Sci. USA 104, 8316-8321 (2007).

107 Grohmann D, Corradi V, Elbasyouny M et al.: Small molecule inhibitors targeting HIV-1 reverse transcriptase dimerization. Chembiochem 9, 916-922 (2008).

108 Schramm HJ, de Rosny E, ReboudRavaux M, Buttner J, Dick A, Schramm W: Lipopeptides as dimerization inhibitors of HIV-1 protease. Biol. Chem. 380, 593-596 (1999).

109 Lee MS, Craigie R: Protection of retroviral DNA from autointegration: involvement of a cellular factor. Proc. Natl Acad. Sci. USA 91, 9823-9827 (1994).

110 Daniel R, Katz RA, Skalka AM: A role for DNA-PK in retroviral DNA integration. Science 284, 644-647 (1999).

111 Violot S, Hong SS, Rakotobe D et al:: The human polycomb group EED protein interacts with the integrase of human immunodeficiency virus type 1. J. Virol. 77, 12507-12522. (2003)

112 Hamamoto S, Nishitsuji H, Amagasa T, Kannagi M, Masuda T: Identification of a novel human immunodeficiency virus type 1 integrase interactor, Gemin2, that facilitates efficient viral cDNA synthesis in vivo. J. Virol. 80, 5670-5677 (2006).

113 Farnet CM, Bushman FD: HIV-1 cDNA integration: requirement of HMG I(Y) protein for function of preintegration complexes in vitro. Cell 88, 483-492 (1997). 


\section{REVIEW || Thys, Busschots, McNeely, Voet, Christ \& Debyser}

114 Parissi V, Calmels C, De Soultrait VR et al:: Functional interactions of human immunodeficiency virus type 1 integrase with human and yeast HSP60. J. Virol. 75, 11344-11353 (2001).

115 Fassati A, Gorlich D, Harrison I, Zaytseva L, Mingot JM: Nuclear import of HIV-1 intracellular reverse transcription complexes is mediated by importin 7. EMBO J. 22, 3675-3685 (2003).

116 Kalpana GV, Marmon S, Wang W, Crabtree GR, Goff SP: Binding and stimulation of HIV-1 integrase by a human homolog of yeast transcription factor SNF5. Science 266, 2002-2006 (1994).

117 Cherepanov P, Maertens G, Proost P et al:: HIV-1 integrase forms stable tetramers and associates with LEDGF/p75 protein in human cells. J. Biol. Chem. 278, 372-381 (2003).

- Landmark paper describing the discovery of LEDGF/p75 as cofactor of HIV integrase.

118 Cereseto A, Manganaro L, Gutierrez MI et al.: Acetylation of HIV-1 integrase by $\mathrm{p} 300$ regulates viral integration. $E M B O J .24$, 3070-3081 (2005).

119 Willetts KE, Rey F, Agostini I et al.: DNA repair enzyme uracil DNA glycosylase is specifically incorporated into human immunodeficiency virus type 1 viral particles through a Vpr-independent mechanism. J. Virol. 73, 1682-1688 (1999).

120 Mousnier A, Kubat N, Massias-Simon A et al.: von Hippel Lindau binding protein 1-mediated degradation of integrase affects HIV-1 gene expression at a postintegration step. Proc. Natl Acad. Sci. USA 104, 13615-13620 (2007).

121 Asante-Appiah E, Skalka AM: HIV-1 integrase: structural organization, conformational changes, and catalysis. $A d v$. Virus Res. 52, 351-369 (1999).

122 Engelman A, Craigie R: Identification of conserved amino acid residues critical for human immunodeficiency virus type 1 integrase function in vitro. J. Virol. 66, 6361-6369 (1992).

123 Engelman A, Bushman FD, Craigie R: Identification of discrete functional domains of HIV-1 integrase and their organization within an active multimeric complex. EMBO J. 12, 3269-3275 (1993).

124 Bushman FD, Wang B: Rous sarcoma virus integrase protein: mapping functions for catalysis and substrate binding. J. Virol. 68, 2215-2223. (1994).
125 Jenkins TM, Engelman A, Ghirlando R, Craigie R: A soluble active mutant of HIV-1 integrase: involvement of both the core and carboxyl-terminal domains in multimerization. J. Biol. Chem. 271, 7712-7718 (1996)

126 Botbol Y, Raghavendra NK, Rahman S, Engelman A, Lavigne M: Chromatinized templates reveal the requirement for the LEDGF/p75 PWWP domain during HIV-1 integration in vitro. Nucleic. Acids Res. 36, 1237-1246 (2008).

127 Turlure F, Maertens G, Rahman S, Cherepanov P, Engelman A: A tripartite DNA-binding element, comprised of the nuclear localization signal and two AT-hook motifs, mediates the association of LEDGF/ p75 with chromatin in vivo. Nucleic Acids Res. 34, 1663-1675 (2006).

128 Singh DP, Kimura A, Chylack LT Jr et al.: Lens epithelium-derived growth factor (LEDGF/p75) and p52 are derived from a single gene by alternative splicing. Gene 242, 265-273 (2000)

129 Ge H, Si Y, Roeder RG: Isolation of cDNAs encoding novel transcription coactivators p52 and 75 reveals an alternate regulatory mechanism of transcriptional activation. EMBO J. 17, 6723-6729 (1998). 